\title{
Major Emerging Viral Zoonosis Reported in Nigeria: A Review
}

\author{
Aiyedun, J O ${ }^{1^{*}}$, Oludairo, O. O. ${ }^{1^{*}}$, Nwoha R I $\mathrm{O}^{2}$ and Daodu B. O. ${ }^{3}$ \\ ${ }^{1}$ Department of Veterinary Public Health and Preventive Medicine, \\ Faculty of Veterinary Medicine, University of Ilorin \\ ${ }^{2}$ Department of Veterinary Medicine Micheal Okpara University of Agriculture, \\ Umudike, Abia State \\ ${ }^{3}$ Department of Veterinary Microbiology, Faculty of Veterinary Medicine, University of Ilorin
}

Accepted November, 2021 and Published December, 2021

\begin{abstract}
This review paper is aimed to provide comprehensive information on emerging and re-emerging viral zoonoses, factors contributing to the emergence and re-emergence of these diseases and prevention and control measures against these viral zoonotic diseases. Emerging zoonoses like avian influenza, ebola virus disease and Lassa fever are those infections, in which the incidence in humans and animals have either increased during the last two decades or threaten to increase shortly. Re-emerging zoonoses like rabies are those that have reappeared after a significant decline in their incidence. Emerging and re-emerging diseases are causing devastating effects nationally and internationally, with millions of people infected and billions of money spent. The factors contributing to the emergence and re-emergence of zoonoses are viral adaptation, antigenic drift and shift, climatic conditions, international travel, globalization and trade. To prevent both human and animal deaths and to avoid potential economic burdens associated with emerging and re-emerging viral zoonotic diseases, there should be good control and prevention methods for these diseases such as good epidemiological survey, improved diagnostic facility, avoidance of global warming and working in collaboration with all stakeholders.
\end{abstract}

Keywords: Emerging, Re-emerging, Viral Zoonoses, Nigeria.

*Corresponding author:

email:olaaiyedun@yahoo.com; and oludairo@homail.com 


\section{INTRODUCTION}

Viral zoonoses are diseases of viral aetiology that can be transmitted between non-human vertebrates and humans including any detriment to the health and quality of human life from relationships with lower vertebrates, edible or toxic invertebrate animals. Emerging zoonoses are newly evolved, discovered or recognized diseases that recently increased in incidence, expanded geographically or expanded in the host or vector range or just jumped from animal to human populations. Emerging zoonotic infectious diseases could be a consequence of intrinsic properties of the virus itself such as a high mutation rate (influenza A virus). The newly appearing infections or those spreading to new areas result from distortion of the ecological balances and changes in geographical locations [1]. Reemerging zoonoses are infectious agents that have been known for some time in an area, had fallen to such low levels that they were no longer considered public health problems and are now showing upward trends in incidence or prevalence. It is the re-appearance of a known infection after a decline in incidence. It also refers to those diseases which were easily controlled previously by antimicrobials but now have developed new resistance to different drugs [2].

\section{Rabies}

Rabies remains one of the most feared and important public health threats in Nigeria $[3,4]$. It is deadly and is caused by neurotropic viruses of the genus lyssavirus. The genus has about 18 genotypes which include classical rabies virus (RABV), Lagos bat virus (LBV), Mokola virus (MOKV), Duvenhage virus (DUVV),
European bats lyssavirus 1 (EBLV- 1), European bats lyssavirus 2 (EBLV-2), Australian bat lyssavirus (ABLV), Aravan virus (ARAV), Khujand virus (KHUV), Irkut virus (IRKV) and West Caucasian bat virus (WCBV). Others include Shimoni bat virus (SHIBV), Bokeloh bat lyssavirus (BBLV), Ikoma lyssavirus (IKLV), Taiwan bat lyssavirus (TBLV). Gannoruwa bat lyssavirus (GBLV), Kotolahti bat lyssavirus (KBLV) and Lleida bat lyssavirus (LLEBV) [6].

Rabies virus is a single-stranded, negativesense RNA virus, maintained in nature by several animal reservoirs [7]. Rabies is a serious zoonosis in Africa and Asia [5]. While dogs are the principal vector for human rabies and are responsible for more than $98 \%$ of human cases [8], bats maintain the virus in the environment acting as a reservoir host. Various species of bats and wild carnivores maintain the sylvatic cycle of rabies. Therefore, rabies control in the urban center must involve dogs, especially stray dogs which are usually unvaccinated. Additionally, the population of reservoir hosts of rabies (bats and wild carnivores) must be controlled and or vaccinated. However, several challenges persist in developed countries as it is difficult, sometimes less productive to end rabies virus transmission in wildlife especially through vaccination programs. The availability of rabies hosts as well as unlimited movement, especially bats, has made them unique in the global spread of rabies. Generally, rabies prevention can be achieved by elimination of exposure and by vaccination through preexposure prophylaxis and post-exposure treatment. Pre-exposure rabies prophylaxis affords a measure of protection for 
unrecognized rabies exposures for those at risk including veterinarians, dog breeders/caregivers, veterinary students and wildlife workers [9, 10]. Post-exposure treatment is recommended following exposure to a potentially rabid animal and involves treatment of wound and administration of rabies vaccine as well as rabies immune globulin for individuals not previously vaccinated $[11,12]$.

\section{Avian Influenza}

Highly Pathogenic Avian Influenza (HPAI) or bird flu, caused by the highly pathogenic H5N1 influenza virus, has affected several countries in Asia and Africa leading to outbreaks, mass deaths and destruction among avian species especially chickens. HPAI is spread by direct contact with infected birds and indirect contact with the fomite, contaminated aerosol, and humans are mainly infected by contact with infected chickens [13]. The virus can be transmitted from infected chickens to man by consumption of contaminated poultry products causing high mortality in humans [2]. It has been reported that wild birds play an important role as long-distance animal reservoirs of the HPAI virus, however, the role of domesticated local chickens in the transmission and maintenance of influenza has been indicated [14]. The study conducted in Nigeria indicated that several local chickens, mostly reared in rural communities with a vast expanse of wildlife were exposed to low pathogenic avian influenza. Viral virulence is enhanced by antigenic drift (small changes/mutations in the genes of influenza viruses that can lead to changes in the surface proteins HA (hemagglutinin) and NA (neuraminidase) of the virus) and antigenic shift (an abrupt, major change in avian influenza virus, resulting in new HA and or NA proteins which can result in the new flu A subtype) [15].

At present, it is illegal to vaccinate against Avian influenza in several countries because of the fear that such could make the virus become dominant and eventually become endemic. Egypt, which legalized vaccination against $\mathrm{H} 5 \mathrm{~N} 1$, has reported the emergence of several novel influenza A strains [17].

\section{Ebola Virus Disease}

Ebola virus, a member of the Filoviridae family caused the severe hemorrhagic fever. Recognized in 1976 by Frederick Murphy, Veterinarian and Karl Johnson, Physician. They unraveled the mystery behind massive death around River Ebola in the Democratic Republic of Congo [17, 18].

Ebola Virus Disease (EVD), formerly known as Ebola haemorrhagic fever, is a severe, often fatal illness, with a case fatality rate of up to $90 \%$ and no licensed specific treatments or vaccine available for use in people or animals $[19,20]$. Ebola virus (EBOV) distant relative is Marburgvirus (MARV) which also cause severe hemorrhagic fever (HF) in humans and non-human primates. Ebola virus disease is currently classified as a Biosafety level Class 4 pathogen due to its lethal nature [1]. The primary source of infection is unknown; however, the epidemiologic mode of transmission is well defined. Ebola fever outbreaks among humans begin with an index case that is subsequently transmitted to secondary individuals by close physical contact or with blood, body secretions, 
excretions, organ tissue, or semen of infected patients [2, 21, 22]. Local or traditional practices of burial that involve external and internal cleansing of infected corpses are also known to encourage EVD transmission in addition to its emergence and re-emergence [23, 24].

Reports suggest that bats (Order: Chiroptera) are the primary natural hosts, including Old World insectivorous bats (genera Rhinolophus and Miniopterus) and frugivorous bats (family: Pteropodidae). Fruit bats of the genus Rousettus have been implicated as a reservoir of filoviruses in Africa. Bats also play important roles in the sylvatic cycle of the virus and maintenance of the disease $[1,25]$.

Ebola virus infection has been documented through the handling of infected or dead chimpanzees, gorillas, fruit bats, monkeys, forest antelope and porcupines found in the rainforest. Ebola then spreads in the community through human-to-human transmission, with infection resulting from direct contact (through broken skin or mucous membranes) with the blood, secretions, organs or other bodily fluids of infected people, and indirect contact with environments contaminated with such fluids. Burial ceremonies in which mourners have direct contact with the body of the deceased person can also play a role in the transmission of Ebola. Men who have recovered from EVD can still transmit the virus through their semen for up to 7 weeks or more after recovery from the illness [26, 27].

\section{Lassa Fever}

The history of recognized human Arenavirus infection in Africa began with the isolation of Arenavirus in two out of the three patients presented with a mysterious illness in Lassa town, Borno State, Nigeria in 1969. Two of the patients who were medical missionaries, however, died mysteriously while the third patient had a near-fatal illness [28].

Lassa fever is an acute viral hemorrhagic illness caused by the Lassa virus belonging to the family, Arenaviridae. The disease is endemic in Nigeria causing thousands of morbidity and mortality in many states across the country from 1969 till date [28]. Transmission is primarily through contact with Mastomys natalensis rodents' excreta and other infected fluids. The emergence and re-emergence of the infection, distribution and mortality due to Lassa fever in Nigeria have the potentials of spreading across the sub-region, continent and the whole world [29].

Humans contract the virus primarily through direct or indirect contact with the contaminated excreta of Mastomys natalensis rodents (Multimammate rat), which is the natural reservoir for the virus. Lassa fever is characterized by fever, muscle aches, sore throat, nausea, vomiting and neonatal mortality which are associated with the persistent chest and abdominal pain. Antiviral drugs have been used successfully to treat human beings. The earlier a person presents, the better the outcome of treatment. For prevention and control of Lassa fever, the general public should avoid contact with rats, observe good personal hygiene including handwashing with soap and running water regularly, dispose of waste properly and maintain a clean environment so that rats are not attracted, store foods in ratproof containers and cook all foods thoroughly before eating, discourage rodents from entering the house by blocking all possible entry points $[26,30]$. 
Important Factors Contributing to Emerging and Reemerging Viral Zoonoses

Pathogen mutation, climatic conditions, international travel, urbanization, deforestation and globalization and trade are the most common events that were contributing to the emergence and re-emergence of zoonotic diseases

\section{Pathogen Mutation}

Changes in natural conditions, such as genetic reassortment/recombination and horizontal transfer of virulence elements often lead to the genetic evolution of microorganisms, possibly resulting in the transition of microbes from nonpathogenic to pathogenic, from low virulence to high virulence, thus causing the emergence of zoonotic diseases.

This genetic reassortment contributes to newly emerging pathogens of humans and animals, such as the recent emergence of the swineorigin influenza A (H1N1) virus and (H7N9) virus

This genetic recombination in coronaviruses could easily generate novel coronavirus genotypes or species that could cross host species barriers and cause the emergence of major zoonotic diseases. Generally. Segmented viruses, such as members of Arthomyxovidiae and Nairoviridae, have a high tendency of genomic reassortment [31].

\section{Climate Change}

Global temperatures are rising and will increase by $1.8-5.8^{\circ} \mathrm{C}$ by the end of the 21 st century.

The increased temperature can enhance pathogen development, disease transmission, and host susceptibility [32]. Increased temperatures will accelerate the development of mosquitoes. Since mosquitoes lay their eggs in water-filled containers, rainfall often affects larval habitats and vector populations. In some cases, rainfall may alter larval habitats and vector populations. Excessive rain can remove habitats through flooding, while limited rainfall may create new habitats, when water in the rivers is drawn into pools it creates novel breeding sites for a mosquito during the dry season.

Waterborne infectious diseases are also strongly affected by climate change. During times of drought, water scarcity results in poor sanitation, therefore, many people can be exposed to potentially contaminated water. In contrast, excess rainfall and flooding can also cause epidemics of waterborne infectious diseases [33].

Weather and climate can influence host defenses, vectors, pathogens and habitats by reducing host/vector immune system, enhancing pathogen antigenic change and inducing habitant change. Vector-borne and water-borne diseases are both strongly affected by climate. Since arthropod vectors tend to be most active at high temperatures and because water scarcity during droughts often leads to poor sanitation, climate change can be expected to drive the spread of vector-borne diseases and diarrhoea illnesses [32].

\section{International Travel}

The increasing world population and migration of people in search of a job to urban areas, lead to overcrowding, poor sanitation and hygiene, 
which provide an ideal breeding ground for infectious agents [34]. Increased international travel, especially without taking the appropriate vaccine and other protective measures, lead to increased infection in travellers, who subsequently bring the infection back homes on their return. Increased cross-border trade of livestock and wildlife is also of great concern [35]. Trading points serve as mixing pools for humans and dozens of other species before they are conveyed to other markets, sold locally or abroad.

\section{Environment}

This massive urbanization has significant public health implications, increasing the occurrence of emerging and re-emerging zoonoses transmitted by water and air, as well as those diseases transmitted through animals or insects, due to the poor healthcare systems and inadequate infrastructure. Accumulated garbage provides food and habitats for rodents and other stray animals, and inadequate water supplies make it necessary to store water in containers, which will become an ideal habitat for mosquito larvae. These factors contribute to emerging and re-emerging zoonotic diseases related to arthropods and rodents. Urbanization also promotes population movement and migration [36].

Human population growth and overexploitation of the land, such as logging, mining, road construction, and agricultural production, has resulted in deforestation. These changes in turn aggravate the emergence of zoonotic diseases through forest fragmentation, population migration, pathogen introduction, and environmental pollution. Deforestation forces wildlife to leave their habitat, thereby increasing interactions among humans, wildlife and livestock [36].

Food-borne pathogens are also associated with the emergence and re-emergence of zoonotic diseases. Many factors are associated with the emergence and re-emergence of food-borne zoonotic diseases, including the global market in meat and farm animals, the habit of eating raw or undercooked food or wildlife, and the increasingly immune-compromised population [37]. While there is increased monitoring of bacterial and toxin contaminants in an animal food product, the evaluation of the animal product for the virus is at the lower ebb especially in African countries.

\section{Globalization and Trade}

The issue of globalization has been one of the most remarkable changes in our lives over the last two decades. Globalization has been the driving force that has greatly impacted international trade, economics and cultural interactions [39]. Not only are more people travelling, but travel is faster and more culturally widespread and permeates into areas of the world not easily accessible in the past. Human beings, animals and products can circumvent the entire world faster than the incubation period of most pathogens today.

\section{Genetic Basis of Emergence and Re- emergence of Viral Zoonoses}

Viral emergences and re-emergences are facilitated by viral adaptation to a new environment and the capacity of a virus to become dominant in the host, relation to other 
viruses [40]. Many studies with human, animal and plant viruses suggest that viral adaptation are associated with genetic change, mediated by mutation, recombination and genome segment re-assortment during viral replication $[15,41]$. The mutation is a universal mechanism of genetic variation that affects all viruses, while recombination appears to vary greatly in frequency among different viruses while segment re-assortment is restricted to viruses with segmented genomes. Viral adaptation is dependent on the sequence of a viral genome and the physical and biological environments in which the virus is found [40].

\section{Prevention and Control of Emerging and Reemerging Viral Zoonotic Diseases}

Control of emerging and reemerging zoonotic diseases and protection of public health will become more challenging as the world population increases [42]. Control of emerging and re-emerging viral zoonoses' strategies must be chosen in line with the characteristics of the virus, its transmission patterns and environmental stability, its pathogenesis and threat to animal health, productivity and profitability and its zoonotic risk. The most valuable preventive measure is vaccination, if available and recommended. Vaccines, such as rabies, ebola virus disease and avian influenza vaccines are not merely for the protection of individual animal/man but to build up a level of population immunity sufficient to break chains of transmission $(70 \%$ coverage of the target population).

To prevent and control emerging and reemerging zoonoses several major steps should be taken such as investigation and collaboration, development of advanced diagnosis and surveillance systems, international and interdisciplinary intervention strategies, applied epidemiological and ecological communication [42].

\section{Conclusion and Recommendations}

The involvement of wildlife in rabies transmission enhance the maintenance of the cycle of the disease. The movement and migration of wildlife especially bats also aid the spread of the disease from one region to the other. Over $70 \%$ coverage of rabies vaccination in dogs could help in the control of the disease.

The first occurrence of Lassa fever was in Nigeria, where multimammate rats are sources of contamination to food and the environment especially in places where hygiene is poor, improved personal and environmental hygiene will help in the prevention and control of this emerging viral zoonosis.

The virulence of the avian influenza virus is enhanced by antigenic drift and shift. The application of vaccines to birds in cases of this emerging zoonosis is illegal in Nigeria where depopulation and decontamination are the recommended methods of control of the disease.

Contact with dead infected people by mourners and relatives and wildlife reservoirs have been reported to help maintain the cycle of the disease over the years. Avoiding contact with infected persons/bodies, good personal/environmental hygiene and vaccination are reportedly effective in the control and prevention of Ebola virus disease. 


\section{REFERENCES}

1. World Health Organization (WHO) (2014). Response Team; Ebola virus Disease in West Africa; the first 9 months of the epidemic and forward projections. NEngl J Med 8 (4) 37-45

2. Centre for Disease Control CDC (2010). Antibiotic / Antimicrobial Resistance (AR / AMR). Available at: https://www.cdc.gov/drugresistance/in dex.html Accessed 22nd September, 2021. .

3. Ogunkoya, A.B.; Will, A.L. and Ezeokoli, C.D. (1984): Rabies in Oyo State in Nigeria: 1971-1982. International Journal of Zoonoses. 11: 84-94.

4. Aiyedun, J.O. (2011): Epidemiology of Canine Rabies in Ilorin, Nigeria. A PhD Thesis in the Department of Veterinary Public Health and Preventive Medicine, University of Ibadan, Ibadan Nigeria pp248.

5. Wilsmore, T.; Hamblin, C.; Taylor, N.; Taylor, W. and Watson, B. (2006): Qualitative Veterinary Risk Assessment of the Introduction of Rabies into the United Kingdom. A report prepared for the Department for Environment, Food and Rural Affairs (Defra).

6. The World Organization for Animal Health (OIE) (2018). Scientific and Technical review. Vol 37 No 2. Ava i 1 a b le a t : https://www.oie.int/en/what-we$\mathrm{do} / \mathrm{publications/scientific-and-}$ technical-review/. Accessed, 1st November, 2021.

7. Aiyedun J O, Oludairo O O, Olorunshola I D and Okoli C P (2017a). Strategies for control, prevention and elimination of urban rabies in west
Africa. Assuit Vet Med J 63 (153) $237-$ 241

8. Knobel, D.L.; Cleaveland, S.; Coleman, P.G.; Fevre, E.M.; Meltzer, M.I.; Miranda, M.E.G.; Shaw, A.; Zinsstag, J. and Meslin, F.X. (2005): Re-evaluating the burden of rabies in Africa and Asia. Bulletin of World Health Organization. 83(5); 360-368.

9. Daodu, O.B. and Oluwayelu, D.O. (2016). Rabies Knowledge and preexposure Vaccination Status of Clinical Veterinary Medicine Students in Nigeria. Vom Journal of Veterinary Science 11, 117-125.

10. Daodu, O.B, Daodu, O.C and Olorunshola, I.D. (2017). Rabies vaccination status among occupationally exposed humans in Nigeria. Nigerian Veterinary Journal, $38(3)$.

11. World Health Organization (WHO) (2018). WHO Expert Consultation on R a bies. Avai $1 \mathrm{able}$ at:https://apps.who.int, iris , 9789240690943. Accessed 22nd September. 2021.

12. Aiyedun $\mathrm{J} \mathrm{O}$, Oludairo $\mathrm{O} \mathrm{O}$, and Olorunshola I D (2017b). Roles of wildlife in epidemiology of rabies: a mini review. Journal of Advanced Veterinary and Animal Research 4 (2) 117-124.

13. Centers for Disease Control and Prevention (CDC) (2018). Highly Pathogenic Asian Avian Influenza A (H5N1) Virus. Available at: https://www.cdc.gov/flu/avianflu/h5n1 -virus.htm. Accessed $22^{\text {nd }}$ September, 2021. 
14. Daodu O.B., Jegede H.0, Aiyedun J.O., Oludairo O.O., Olorunshola I.D., Daodu O.C., A. Ajadi and Ambali S.F. (2020). Surveillance for avian influenza virus in captive wild birds and indigenous chickens in Nigeria. Tropical Animal Health and

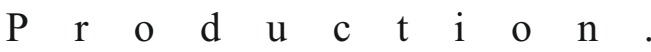
https://doi.org/10.1007/s11250-02002265-y

15. World Health Organization (WHO), (2021). How Flu Viruses Can Change: "Drift" and "Shift". Available at: https://www.cdc.gov/flu/about/viruses/ change.htm. Accessed 1st November, 2021.

16. Kandeil, A., Mostafa, A., El-Shesheny, R., El-Taweel, A. N., Gomaa, M., Galal, H., Kayali, G., \& Ali, M. A. (2017). Avian influenza H5N1 vaccination efficacy in Egyptian backyard poultry. Vaccine, 35(45), 6195-6201. https://doi.org/10.1016/j.vaccine.2017. 09.040

17. Francis, D P; Smith, D.H; Highton, R B; Simpson, P.L; Isaiah, M. D; Anthony, L G; Ali, A. I and Babiker, E (2014). Ebola Fever in Sudan, 1976; Epidemiological Aspects of the dis e a s e s A a ilable a t ;http;//www.ncbi.nlm.gov/pmc/article/ PMC2395561. Accesssed on $26^{\text {th }}$ September, 2014.

18. George, A, J; Leroy, E, M; Renault, A. A; Benissan C. T and Nabias R. J (1999). Ebola haemorrhagic Fever Outbreak in Gabon, 1994-1997; Epidemiological and Health Control Issues. The Journal of infectious Diseases 179; 65-75.

19. Centre for Disease Control CDC (2 0001$)$. Outbreak of Ebola Haemorrhagic Fever- Uganda August 200- January 2001, MMWR 50; 05.
20. Mbonye, A K; Wamala, J. F; Nanyunja, M; Opio, A; Makunbi,I and Aceng, J. R (2014).. Ebola vial hemorrhagic disease outbreak in West AfricaLessons from Uganda. Journal of Africa Health Sci 14 (3); 495-501.

21. Umeora O. U. J; Emma-Echiegu, N. B; Umeora M C and Ajayi N (2014). Ebola virus Disease in Nigeria; The panic and cultural threat. Africa Journal Med Health Sci. 13 (1); 1-5.

22. World Health Organization (WHO) (2015). Ebola virus Disease http://www.who.int/csr/resources/publ ications/ebola/ebola-case. Accessed on $9^{\text {th }}$ December, 2015.

23. Kass N (2014). Ebola, Ethics and Public Health; What Next Annals of internal Medicine. Available at; https://www.acpjournals.org/doi/10.7 326/m14-1864.. Accessed 22nd Seeptember, 2021.

24. Aiyedun, J.O. and Oludairo, O.O. (2016). Epidemiological notes on Ebola Virus Disease in Nigeria. Assiut Veterinary Medical Journal, 62: 168171.

25. Roddy P; Howard, N; Kerkhove, M D V,; Lutwama, J; Wamala, J ; Yoti, Z; Colebunders, R; Palma, P. P; Sterk, E;,Jeffs, B; Herp, M.V and Borchert, M (2012). Clinical Manifestation and Case Management of Ebola Hemorrgagic Fever caused by a newly identified virus strain, Bundibugyo, Uganda, 2007-2008. PLOSONE 7 (12); e52986. Doi; 10. 1371/ journal. Pone. 0052986.

26. Centers for Disease Control and Prevention (CDC) (2021). Ebola (Ebola Virus Disease. Available at: https://www.cdc.gov/vhf/ebola/transm ission/index.html. Accessd 22nd 
September, 2021.

27. Federal Ministry of Health FMH (2014). Standard Operating Procedure for contact Tracing and follow up during Ebola Virus Disease Outbreak August 2014, 1-13.

28. Tomori O, Fabiyi A, Sorungbe A, Smith A, McCormick JB (1988). Viral hemorrhagic fever antibodies in Nigerian populations. Am J Trop Med Hyg 38: 407-10

29. Fisher-Hoch SP, Tomori O, Nasidi A, Perez-Oronoz GI, Fakile Y, Hutwagner L, (1995). Review of cases of nosocomial Lassa fever in Nigeria: the high price of poor medical practice. BMJ 311: 857-9.

30. Keenlyside RA, McCormick JB, Webb PA, Smith E, Elliott L, Johnson KM. (1983). Case-control study of Mastomys natalensis and humans in Lassa virus-infected households in Sierra Leone. Am J Trop Med Hyg 32: 829-37.

31. McDonald, S. M., Nelson, M. I., Turner, P. E., \& Patton, J. T. (2016). Reassortment in segmented RNA viruses: mechanisms and outcomes. Nature reviews. Microbiology, 14(7), $\begin{array}{lllllll}4 & 4 & 8 & - & 4 & 6 & 0\end{array}$. https://doi.org/10.1038/nrmicro.2016.4 6

32. Forster, P.M., Forster, H.I. and Evans, M.J. (2020) Current and future global climate impacts resulting from COVID19. Nat. Clim. Chang. ; 10, 913-919. https://doi.org/10.1038/s41558-0200883-0

33. World Health Organization (WHO) (2021). Impacts on health of climate extremes. Available at: ht t p s:// w w w.w ho. int, climatechangechap5. Accessed 1st November, 2021.

34. Neiderud C. J. (2015). How urbanization affects the epidemiology of emerging infectious diseases. Infect. Ecol. \& epidemiol., 5, 27060. https://doi.org/10.3402/iee.v5.27060

35. Bentley, J.W., Robson, M. and Sibale, B.B. (2012). Travelling Companions: Emerging Diseases of People, Animals and Plants Along the MalawiMozambique Border. Hum Ecol 40, $557-569 \quad\left(\begin{array}{llll}2 & 0 & 1 & 2\end{array}\right)$. https://doi.org/10.1007/s10745-0129503-6

36. Olorunfemi J F and Odita C O, (1998). Land use and solid waste generation in Ilorin, Kwara State, Nigeria. The environmentalist 18, 67-75.

37. Olorunfemi J F and Odita C O,(1985). The growth of Ilorin; a documentation i n a e rial photography. Environmentalist international, 11, 509-514.

38. Bintsis T. (2017). Foodborne pathogens. AIMS Microbiol. Jun $29 ; 3(3): 529-563$. d o i : 10.3934/microbiol.2017.3.529. PMID: 31294175 ; PMCID: PMC6604998.

39. Yaya, S., Yeboah, H. and Charles, C. H. (2020). Ethnic and racial disparities in COVID-19-related deaths: counting the trees, hiding the forest. BMJ Global $H$ e a l th; 5 : e 002913 . doi:10.1136/bmjgh-2020-002913

40. Domingo E. (2010). Mechanisms of viral emergence. Vet. Res., 41(6), 38. https://doi.org/10.1051/vetres/201001 0

41. Domingo E. (2007). Virus evolution, in: Fields Virology, 5th ed., Lappincott Williams \& Wilkins, Philadelphia. 
42. Excler, JL., Saville, M. and Berkley, S. (2021). Vaccine development for emerging infectious diseases. Nat Med

27, 591-600.

https://doi.org/10.1038/s41591-02101301-0

43. Kelly, T.R., Machalaba, C. and Karesh, W.B. (2020). Implementing One Health approaches to confront emerging and reemerging zoonotic disease threats: lessons from PREDICT. One Health O u t 1 o o k $2, \quad 1$. https://doi.org/10.1186/s42522-0190007-9. 